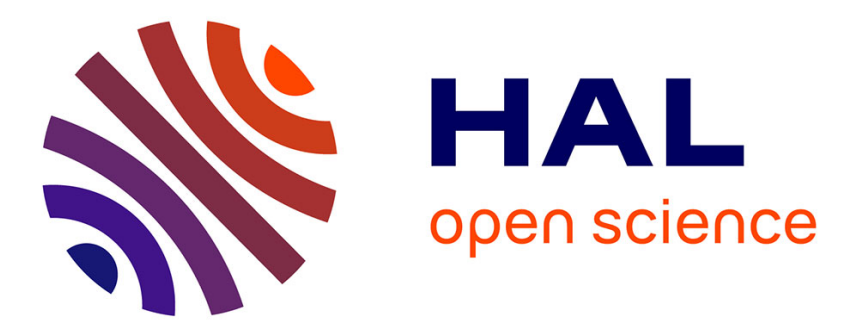

\title{
Determination of deposited flux and energy of sputtered tungsten atoms on every stages of transport in HiPIMS discharge
}

\author{
Mikaël Désécures, Ludovic de Poucques, Jamal Bougdira
}

\section{- To cite this version:}

Mikaël Désécures, Ludovic de Poucques, Jamal Bougdira. Determination of deposited flux and energy of sputtered tungsten atoms on every stages of transport in HiPIMS discharge. Plasma Sources Science and Technology, 2017, 26 (2), pp.025003. 10.1088/1361-6595/26/2/025003 . hal-02314383

\author{
HAL Id: hal-02314383 \\ https://hal.science/hal-02314383
}

Submitted on 12 Oct 2019

HAL is a multi-disciplinary open access archive for the deposit and dissemination of scientific research documents, whether they are published or not. The documents may come from teaching and research institutions in France or abroad, or from public or private research centers.
L'archive ouverte pluridisciplinaire HAL, est destinée au dépôt et à la diffusion de documents scientifiques de niveau recherche, publiés ou non, émanant des établissements d'enseignement et de recherche français ou étrangers, des laboratoires publics ou privés. 
archives-ouvertes

\title{
Determination of deposited flux and energy of sputtered tungsten atoms on every stages of transport in HiPIMS discharge
}

\author{
Mikaël Désécures, Ludovic de Poucques, Jamal Bougdira
}

\section{To cite this version:}

Mikaël Désécures, Ludovic de Poucques, Jamal Bougdira. Determination of deposited flux and energy of sputtered tungsten atoms on every stages of transport in HiPIMS discharge. Plasma Sources Sci.

Technol, 2017, 26. hal-02314383

\section{HAL Id: hal-02314383 \\ https://hal.archives-ouvertes.fr/hal-02314383}

Submitted on 12 Oct 2019

HAL is a multi-disciplinary open access archive for the deposit and dissemination of scientific research documents, whether they are published or not. The documents may come from teaching and research institutions in France or abroad, or from public or private research centers.
L'archive ouverte pluridisciplinaire HAL, est destinée au dépôt et à la diffusion de documents scientifiques de niveau recherche, publiés ou non, émanant des établissements d'enseignement et de recherche français ou étrangers, des laboratoires publics ou privés. 
Determination of deposited flux and energy of sputtered tungsten atoms on every stages of transport in HiPIMS discharge

This content has been downloaded from IOPscience. Please scroll down to see the full text.

2017 Plasma Sources Sci. Technol. 26025003

(http://iopscience.iop.org/0963-0252/26/2/025003)

View the table of contents for this issue, or go to the journal homepage for more

Download details:

IP Address: 193.50.135.4

This content was downloaded on $03 / 01 / 2017$ at $14: 14$

Please note that terms and conditions apply.

You may also be interested in:

Characterization of energetic and thermalized sputtered tungsten atoms using tuneable diode-laser induced fluorescence in direct current magnetron discharge

$M$ Desecures, $L$ de Poucques and J Bougdira

On the HiPIMS benefits of multi-pulse operating mode

O Antonin, V Tiron, C Costin et al.

Tunable diode-laser induced fluorescence on $\mathrm{Al}$ and $\mathrm{Ti}$ atoms in low pressure magnetron discharges

$C$ Vitelaru, $C$ Aniculaesei, $L$ de Poucques et al.

Space-resolved velocity and flux distributions of sputtered Ti atoms in a planar circular magnetron discharge

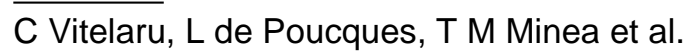

Plasma diagnostics for understanding the plasma-surface interaction in HiPIMS discharges: a review Nikolay Britun, Tiberiu Minea, Stephanos Konstantinidis et al.

Study of the transport of titanium neutrals and ions

Ludovic de Poucques, Jean-Christophe Imbert, Caroline Boisse-Laporte et al.

Two dimensional spatial Argon metastable dynamics in HiPIMS discharges

Alexander Kanitz, Ante Hecimovic, Marc Böke et al.

Time-domain and energetic bombardment effects on the nucleation and coalescence of thin metal films on amorphous substrates

D Magnfält, V Elofsson, G Abadias et al. 


\title{
Determination of deposited flux and energy of sputtered tungsten atoms on every stages of transport in HiPIMS discharge
}

\author{
M Desecures ${ }^{12}$, L de Poucques ${ }^{12}$ and J Bougdira ${ }^{12}$ \\ 1 Université de Lorraine, Institut Jean Lamour UMR 7198, Vandoeuvre-lès-Nancy, F-54506, France \\ 2 CNRS, Institut Jean Lamour UMR 7198, Vandoeuvre-lès-Nancy, F-54506, France \\ E-mail: mikael.desecures@univ-lorraine.fr
}

Received 26 July 2016, revised 7 October 2016

Accepted for publication 7 November 2016

Published 23 December 2016

\begin{abstract}
A time-resolved tunable diode-laser (DL) induced fluorescence (TR-TDLIF) technique has been used to identify different populations of atoms (on different stages of transport) to determine their corresponding deposited energy and flux. The temporal dimension permits the splitting of the processes of sputtering during the discharge and particles transport in the post-discharge where atoms and flux velocity distribution fonctions (AVDF, FVDF) of each population were measured varying the discharge parameters (power, voltage, pressure, and distance from target). Tungsten (W) was chosen, being an interesting case in terms of sputtered atom transport, considering its weight which implies weak changes of directivity or energy transfer after collisions with the buffer gas. The high temporal and spectral resolutions of TR-TDLIF are the keys for the distinction of the atoms populations and the stage corresponding to the transition from the ballistic to diffusive regime of transport was observed for the first time and named quasi-diffusive regime. Thus, the ability to dissociate populations of atoms and to determine their deposited flux and energy may be of great interest to adjust film properties as desired for applications.
\end{abstract}

Keywords: time resolved tunable diode laser induced fluorescence, transport, tungsten, magnetron sputtering, high power impulse magnetron sputtering (HiPIMS), atoms velocity distribution fonction of sputtered atoms

(Sorne figures may appear in colour only in the online journal)

\section{Introduction}

Magnetron sputter deposition is an established and widely used method for the growth of thin films. Nevertheless, the high level of expectations regarding new applications require a better understanding, controlling, mastering of basic processes goveming atoms transport in the view of process optimization. The spatio-temporal knowledge of the properties of incoming film-forming atomic species in HiPIMS (high power impulse magnetron sputtering) may be exploited to adjust the film physical properties as desired for applications [1-6] and for modelling both plasma and particle-depositing processes $[7,8]$.
In HiPIMS process, the degree of ionization of the sputtered vapour is usually greater than $50 \%[9,10]$. Nevertheless, a significant fraction of sputtered neutral atoms remains and may influence thin film deposition properties. Ion energy can be fixed by polarizing a substrate, while neutrals are difficult to control. Experimental measurements are then required for a better understanding of their transport properties in view of a potential optimization in terms of number or energy when reaching a substrate.

Diagnostics using diode laser (DL) are among the most powerful techniques for studying plasmas since they are not intrusive and allow the acquisition of accurate experimental results on ground or metastable state of particles. A few studies using such techniques have been performed on sputtered 
atoms such as aluminium (Al) [11-13], titanium (Ti) [13-18] and tungsten $(\mathrm{W})$ atoms $[19,20]$. A fraction of them are timeresolved and they are only absorption DL based techniques $[12,15,18]$ (absolute measurements but not giving the spatial resolution as restricted to conditions for which the absorption can be assumed homogeneous along the laser beam pathway). Fluorescence DL based techniques [20] give access to local measurements (spatial resolution) and the temporal dimension permits the splitting of both the process of sputtering during the discharge and the process of particles transport in the postdischarge. Thus, a time-resolved tunable DL-induced fluorescence (TR-TDLIF) method calibrated with TR-TDLAS (time resolved tunable DL absorption spectroscopy) was used in order to determine the spatio-temporal evolution of absolute atom and flux velocity distribution functions (AVDF and FVDF) in the post-discharge.

W was chosen for its applications in thin film deposition (WC [21] and $\mathrm{WO}_{X}$ [22]) and also being an interesting case in term of sputtered atom transport, considering its weight which implies weak changes of directivity or energy transfer after collisions with the buffer gas. The TR-TDLIF temporal and spectral resolutions give the ability to distinguish different atoms populations with their characteristic regimes of transport and thus, provide insight into transition from the ballistic to diffusive regimes. AVDF and FVDF of different atoms population were measured varying the discharge parameters (power, voltage, pressure, distance from target, etc). The evolution of those distributions highlighted the different stages of the atoms transport which shows an intermediate regime between ballistic and diffusive ones and was named quasidiffusive. The properties of those quasi-thermalized atoms are then discussed.

At typical distances along the axial direction $(z=5$ and $9 \mathrm{~cm}$ ) used for magnetron sputtering processes (DC_direct current and HiPIMS_high power impulse magnetron sputtering), deposited flux and energy as function of time and over a HiPIMS period for the different populations of $\mathrm{W}$ neutral atoms were characterized under the varying parameters.

\section{TR-TDLIF experimental setup and data analysis}

Figure 1 represents the TR-TDLIF technique [20] experimental set-up including its electrical and optical arrangements. The beam of the excitation source, a $15 \mathrm{~mW}$ single-mode tunable diode laser (Toptica Phototonics DL 100), is oriented perpendicularly to the target surface (for axial measurements) and towards the racetrack centre at $R_{0}=1.3 \mathrm{~cm}$ where the plasma-generated sputtering of $\mathrm{W}$ atoms is mostly localized (as shown in figure 1 bottom picture). It crosses the $(1 * 1$ * 3) $\mathrm{mm}^{3}$ probing volume centred at $z(z=3,5,9 \mathrm{~cm})$ and $R_{0}=1.3 \mathrm{~cm}$ with its $3 \mathrm{~mm}$ edge lying along $z$. The magnetron plasma is localized close to the target with a maximum of plasma light for distances $<3 \mathrm{~cm}$. Consequently, $z=3 \mathrm{~cm}$ is the closest distance accessible to avoid disturbances linked with plasma optical emission. The DL is tuned around the resonance transition at $\lambda_{0}(\mathrm{~W})=407.4358 \mathrm{~nm}$ to a mode-hop free $\sim 9 \mathrm{pm}$ wavelength scan synchronized to the DL-monitored frequency of $5 \mathrm{~Hz}$ (figure 1: inset). The tuning is carried out

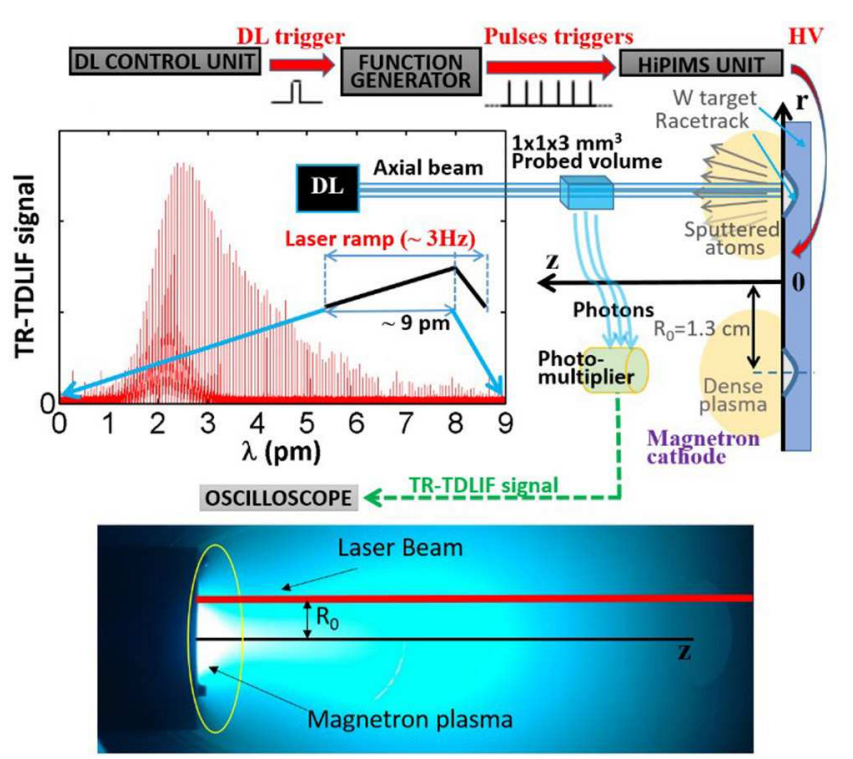

Figure 1. HiPIMS set-up including its electrical and optical arrangements for TR-TDLIF signal measurements (reproduced from [20], copyright 2014 with the permission of AIP Publishing). Figures inset shows a TR-TDLIF profile obtained in a thousand $9 \mathrm{pm}$ DL scans (in order to reduce the signal-to-noise ratio to an acceptable level), with 200 HiPIMS periodic pulses. Bottom picture: typical magnetron sputtering plasma of $\mathrm{W}$ target with laser beam configuration.

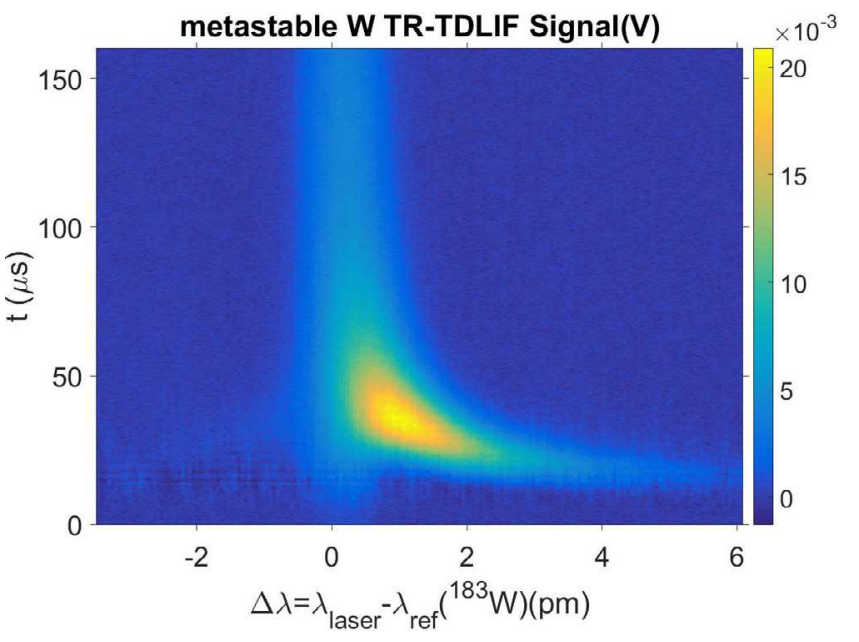

Figure 2. 2D-image of a typical wavelength-time dependent TRTDLIF signal measured at $z=3 \mathrm{~cm} . R_{0}=1.3 \mathrm{~cm} ; p=0.4 \mathrm{~Pa}$; $P_{\mathrm{av}}=120 \mathrm{~W}$.

by adjusting the DL piezo and current. The neutral $\mathrm{W}$ transition from the metastable low-energy level $(0.36 \mathrm{eV}) 5 d^{5}\left({ }^{6} \mathrm{~S}\right) 6 \mathrm{~s}$ to the radiative excited level $5 d^{5}\left({ }^{6} \mathrm{~S}\right) 6 p$ occurs at $\lambda_{0}$ with laser absorption and the fluorescence also emitted at $\lambda_{0}$. We note here that no particular DL is currently available to probe the W's ground state.

The set-up includes the low-frequency $(\sim 5 \mathrm{~Hz})$ and high spectral-resolution DL $(\sim 0.005 \mathrm{pm})$, a fast rise-time pulse generator and a HiPIMS system. The HiPIMS unit was set to deliver 200 pulses during the $\sim 9 \mathrm{pm}$ wavelength scan assuming that a single pulse corresponds to the time evolution of the TR-TDLIF signal at a given wavelength (increment 


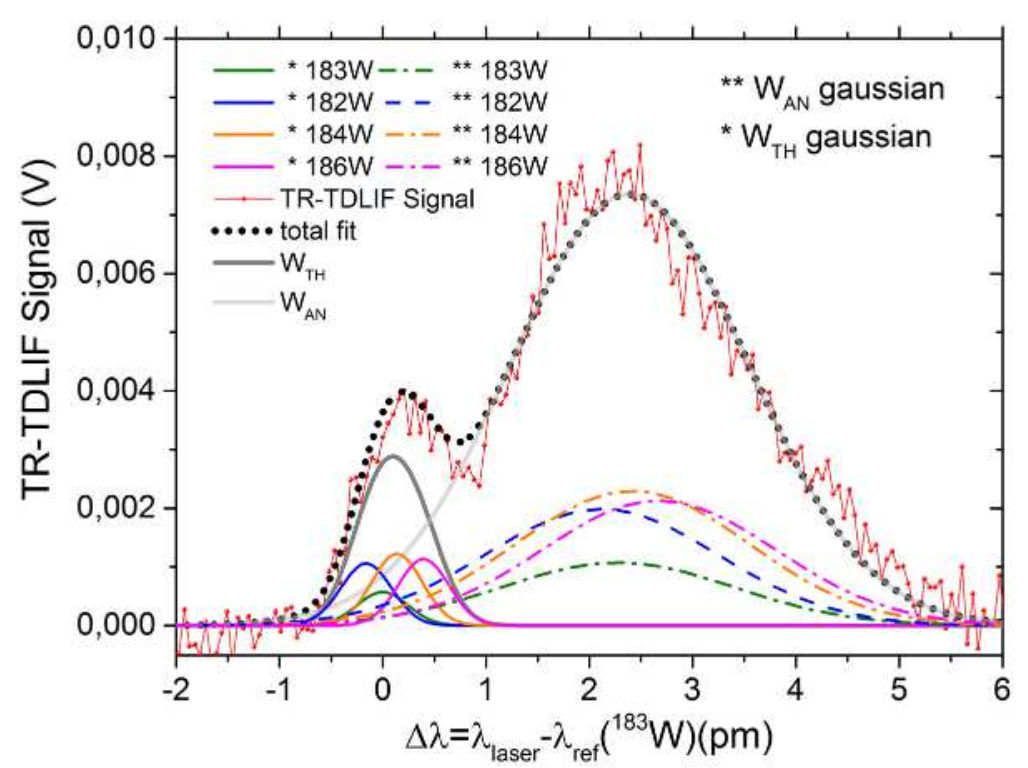

Figure 3. TR-TDLIF signal measured at $t=20 \mu \mathrm{s}$ and its respective $\mathrm{W}_{\mathrm{AN}}$ and $\mathrm{W}_{\mathrm{EN}}$ total fits (groups of Gaussians describing the four W isotopes). $z=3 \mathrm{~cm} ; R_{0}=1.3 \mathrm{~cm} ; p=0.4 \mathrm{~Pa} ; P_{\mathrm{av}}=120 \mathrm{~W}$.

of $0.045 \mathrm{pm}$ between two HiPIMS pulses). A stable pulsed plasma was thus formed under the following conditions: $\mathrm{Ar}$ pressure $p=0.4$ or $4 \mathrm{~Pa}$, discharge voltage $V=350-600 \mathrm{~V}$, average discharge current $I=6-20 \mathrm{~A}$, a pulse period $T=1 \mathrm{~ms}$ and a discharge time $T_{\text {on }}=10 \mu \mathrm{s} . P_{\text {av }}$ is the average magnetron power and $P_{\text {discharge }}$ the discharge power as defined in equation (1).

$$
P_{\mathrm{av}} T=P_{\text {discharge }} T_{\mathrm{on}}
$$

The induced TR-TDLIF signal is recorded every $0.5 \mu$ s with a digital oscilloscope of a second-long trace. For more details, see [20].

From the whole TR-TDLIF signal (figure 1: inset) recorded at $z=3 \mathrm{~cm}$, a typical $2 \mathrm{D}$ picture of the fluorescence signal evolution is shown on figure 2 which is wavelength resolved (resolution of $\sim 0.045 \mathrm{pm}$ or $\sim 30 \mathrm{~m} \mathrm{~s}^{-1}$ ) in abscissa and time resolved in ordinate (resolution of $\sim 0.5 \mu \mathrm{s}$ ). The coma-shaped TR-TDLIF image shows clearly the coexistence of several atomic populations in the probed volume during a post-discharge: the anisotropic atoms $\left(\mathrm{W}_{\mathrm{AN}}\right)$ of high positive velocities (positive $\Delta \lambda$ corresponding to atomic velocity ranging from 0 to $5 \mathrm{~km} \mathrm{~s}^{-1}$ ) crossing the probed volume within the first $50 \mu \mathrm{s}$ (tail of the coma), the thermalized ( $\left.\mathrm{W}_{\mathrm{TH}}\right)$ characterized by a symmetry around $\Delta \lambda=\lambda_{\text {laser }}-\lambda_{\text {ref }}\left({ }^{183} \mathrm{~W}\right.$ ) $=0$ (atomic velocity of $0 \mathrm{~km} \mathrm{~s}^{-1}$ ) at longer times.

Figure 3 displays clearly those two populations coexisting at $t=20 \mu \mathrm{s}$ and characterized by two peaks (the left one to $\mathrm{TH}$ and the right one to AN). At a given time, the AVDFs of each population are determined from fitting Gaussian functions to the measured TR-TDLIF signal taking into account the four $\mathrm{W}$ isotopes natural abundance and resonance shifts (a Gaussian for one isotope) [20]. For more details concerning isotopes see [23]. The origin $\Delta \lambda=0$ or $\lambda_{\text {ref }}$ is fixed arbitrarily along the maximum of the Gaussian fitting the thermalized population ${ }^{183} \mathrm{~W}$ measured on residual atoms on the postdischarge onset. Furthermore, the Gaussians were assumed to possess the same full width at half maximum (FWHM) since all isotopes have the same temperature (the slight differences between their masses were neglected). Thus, each time the fitting procedure is a group of four Gaussians at $\Delta \lambda=0$ for TH atoms and a group of four Gaussians around $\Delta \lambda>0$ for $\mathrm{AN}$ ones. The $\mathrm{W}_{\mathrm{AN}}$ velocity distribution at a fixed $z$ implies velocity selection and fit with Gaussian distributions (for more explanations see [20]) instead of Stephanova and Dew's [24]. The $\operatorname{AVDFs}(\Delta \lambda, t)$ of the populations $\mathrm{W}_{\mathrm{AN}}\left(\operatorname{AVDF}_{\mathrm{AN}}(\Delta \lambda, t)\right)$ and $\mathrm{W}_{\mathrm{TH}}\left(\mathrm{AVDF}_{\mathrm{TH}}(\Delta \lambda, t)\right)$ may then be easily determined.

In order to obtain local quantitative measurements on both energetic and thermalized W sputtered atoms, the TR-TDLIF is calibrated using TR-TDLAS. The latter use is however restricted to conditions for which the absorption can be assumed homogeneous along the laser beam pathway. Therefore, the calibration was achieved in conditions where only the contribution from the thermalized atoms was measured that is far away from target $(z=9 \mathrm{~cm})$, at relatively high pressure $(p=4 \mathrm{~Pa})$ and far from the post-discharge onset at $t=900 \mu \mathrm{s}$. Converting the wavelength scale into velocity scale using Doppler's relation $v=c \cdot \Delta \lambda \lambda$, the result gives $10 \mathrm{~V} \mathrm{~cm} \mathrm{~s}^{-1}$ (area of a Gaussian $\left(v_{z}\right)$ ) being equivalent to $2 \cdot 10^{8}$ part $\cdot \mathrm{cm}^{-3}$. Note that the Doppler broadening (not shown here) at this time is equivalent in axial (fluorescence) and radial (absorption) direction, confirming the isotropy of measured thermalized population of atoms. This consistency was then used to rescale other space-time TR-TDLIF signals, allowing the study of local dynamics of the absolute metastable $\mathrm{W}$ atoms density and flux.

The thermalized and energetic atoms of isotropic and anisotropic velocities distributions respectively constitute the dynamic transport regime in the beginning of the post-discharge. This sputtered atoms dynamic regime is best described by the flux velocity distribution function FVDFs $\left(v_{z}, t\right)$ defined as $v_{z} *$ AVDFs $\left(v_{z}, t\right)$. The absolute total flux velocity distribution function $\mathrm{FVDF}_{\mathrm{TOT}}\left(\mathrm{FVDF}_{\mathrm{AN}}+\mathrm{FVDF}_{\mathrm{TH}}\right)$ is deduced by 


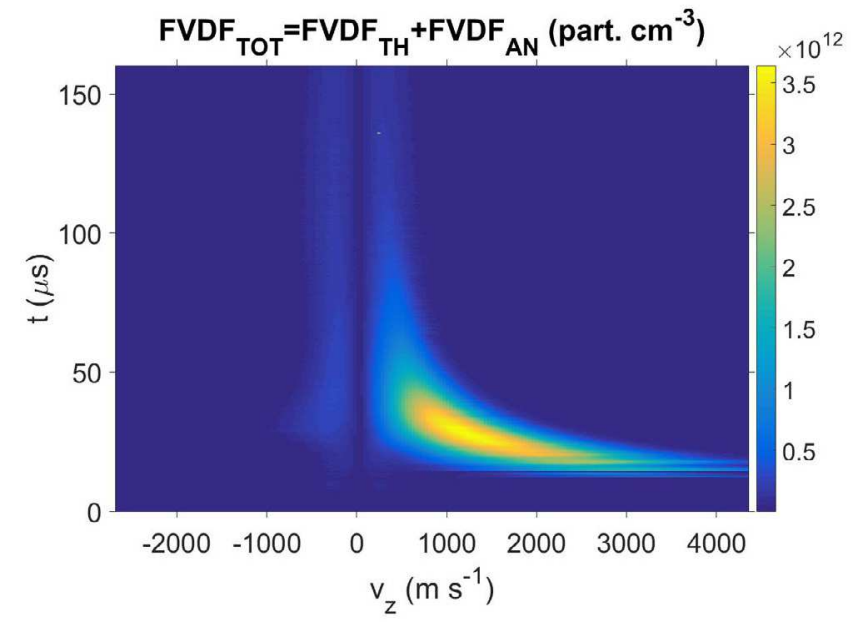

Figure 4. 2D-image of total flux-velocity distribution function $\mathrm{FVDF}_{\mathrm{TOT}}=\mathrm{FVDF}_{\mathrm{EN}}+\mathrm{FVDF}_{\mathrm{TH}}$ of metastable W atoms. $z=3 \mathrm{~cm}$; $R_{0}=1.3 \mathrm{~cm} ; p=0.4 \mathrm{~Pa} ; P_{\mathrm{av}}=120 \mathrm{~W}$.

weighting the natural abundance of any single isotope $\left({ }^{183} \mathrm{~W}\right.$ chosen here) to obtain the total of atoms (the sum of the 4 isotopes) and such that the resonance shift between isotopes of a population is compensated. Figure 4 gives the $\mathrm{FVDF}_{\mathrm{TO}} 2 \mathrm{D}$ evolution. Using this type of representation, it is possible to distinguish more easily the different population of atoms. It can be seen that the energetic atoms of high positive velocities cross the probed volume within the first $50 \mu \mathrm{s}$. For $\mathrm{t}<80$ $\mu \mathrm{s}$, the image exhibits the symmetry around $v=0$, pointing out that only the thermalized atoms cross the probed volume. Further insight into the transition of the energetic metastable $\mathrm{W}$ atoms to thermalized ones may be gained by studying their densities and fluxes.

The areas formed by $\operatorname{AVDF}_{\mathrm{AN}}(v)$ and $\operatorname{AVDF}_{\mathrm{TH}}(v)$ at any given time define respectively the number of metastable atoms per volume unit $[\mathrm{W}]_{\mathrm{AN}}(t)$ and $[\mathrm{W}]_{\mathrm{TH}}(t)$. Similarly, the fluxes passing through a surface unit per time towards the substrate $\Phi_{\mathrm{AN}}(t)$ and $\Phi_{\mathrm{TH}}(t)$ are respectively the areas formed by $\operatorname{FVDF}_{\mathrm{AN}}(t)$ and $\mathrm{FVDF}_{\mathrm{TH}}(t)$. The total density and the flux are then: $[\mathrm{W}]_{\mathrm{TOT}}(t)=[\mathrm{W}]_{\mathrm{AN}}(t)+[\mathrm{W}]_{\mathrm{TH}}(t)$ and $\Phi_{\mathrm{TOT}}(t)=\Phi_{\mathrm{AN}}(t)+\Phi_{\mathrm{TH}}(t)$. The representativeness of TR-TDLIF measurements on the metastable state of sputtered neutral W atoms was checked by a direct comparison between the DL measured atoms fluxes and the deposition rates. The measured atoms flux directed towards the substrate (DIR) of anisotropic $(\Phi \underset{\mathrm{AN}}{\mathrm{int}})$ (equation (2)) and isotropic $\left(\Phi{ }_{\mathrm{TH}}^{\mathrm{int}}\right)$ (equation (3)) atoms was integrated over a HiPIMS period ( $1 \mathrm{~ms})$. The sum of both yields the total flux directed toward the substrate $(\Phi$ int $\operatorname{\text {DIRTot}}()$ (equation $(4))$ which corresponds to the number of deposited atoms and was compared with the deposition rate estimated from the deposition thickness obtained by means of SEM (scanning electron microscopy).

$$
\begin{aligned}
& \Phi_{\mathrm{AN}}^{\mathrm{int}}=\int_{t=0}^{t=1 \mathrm{~ms}} \Phi_{\mathrm{AN}}(t) d t \\
& \Phi_{\mathrm{TH}}^{\mathrm{int}}=\int_{t=0}^{t=1 \mathrm{~ms}} \Phi_{\mathrm{TH}}(t) \mathrm{d} t
\end{aligned}
$$

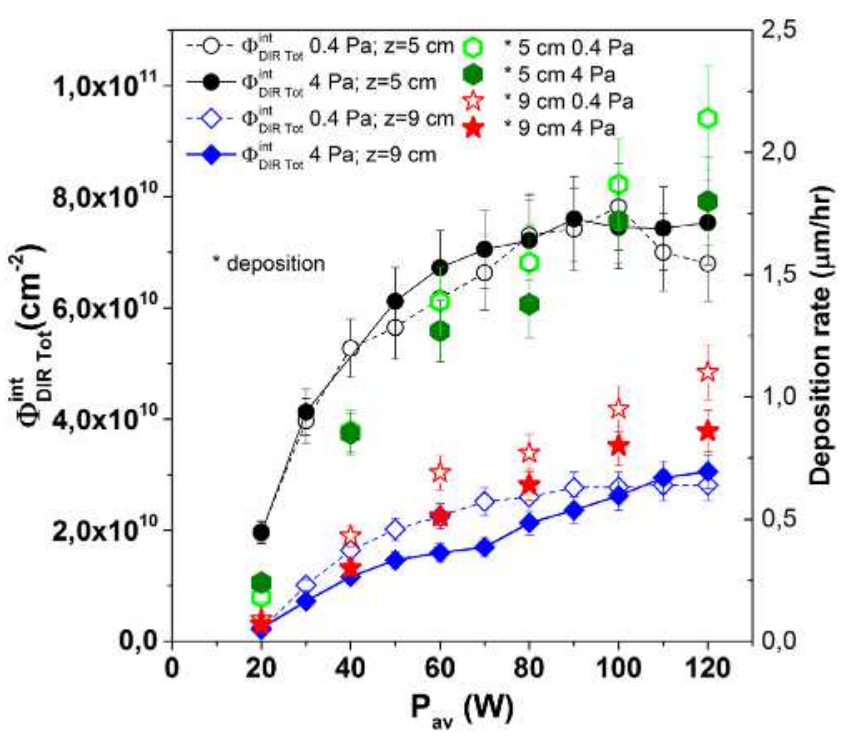

Figure 5. Evolutions of integrated total flux $\Phi$ int $\operatorname{DIR}$ Tot of metastable $\mathrm{W}$ neutral atoms and $\mathrm{W}$ deposition rate at $z=5 \mathrm{~cm}$ and $9 \mathrm{~cm}$, $p=0.4$ and $4 \mathrm{~Pa}$, as function of average magnetron power $P_{\mathrm{av}}$. $R_{0}=1.3 \mathrm{~cm}$.

$$
\Phi_{\mathrm{DIR} T o t}^{\mathrm{int}}=\Phi_{\mathrm{AN}}^{\mathrm{int}}+\Phi_{\mathrm{TH}}^{\mathrm{int}}
$$

Figure 5 shows for two pressures $(0.4$ and $4 \mathrm{~Pa})$ and two distances $(z=5$ and $9 \mathrm{~cm}), \Phi \underset{\text { DIR tot }}{\text { int }}$ and the deposition rates as function $P_{\mathrm{av}}$. Both seem to be in relatively good agreement and this step allows the consideration of the measurements on the metastable state of $\mathrm{W}$ neutrals as being well representative of the total deposited atoms in HiPIMS process (neutrals and ions). Moreover, this agreement indicates that the kinetic is not strongly affected by the electron density $\left(n_{\mathrm{e}}\right)$ and temperature $\left(T_{\mathrm{e}}\right)$ variations in the post-discharge in terms of population or destruction of the metastable level. Being a low energy metastable state $(0.36 \mathrm{eV})$, it can be sensitive to $n_{\mathrm{e}}$ (and less likely to the electron temperature $T_{\mathrm{e}}$ ) and yet there is a good agreement between DL measurements and deposition rates. Thus, it can be assumed that the metastable state is populated in the HiPIMS plasma nearby the target and transported up to the probed volume without any modifications (population or destruction). In our previous studies, the same agreement was found in DC process case [19].

This checking achieved, it becomes possible to study the atoms kinetic considering the metastable evolution as being representative of the neutrals atoms kinetic.

\section{Energetic, thermalized and quasi-thermalized atoms}

\subsection{Highlight of two populations of anisotropic atoms}

The time evolution of TR-TDLIF signal being representative of neutrals kinetic, measurements at several locations along the magnetron axis were performed $(z=3,5,9 \mathrm{~cm})$ in order to get locally some insights into the transition from the ballistic to diffusive regime of atoms transport. 


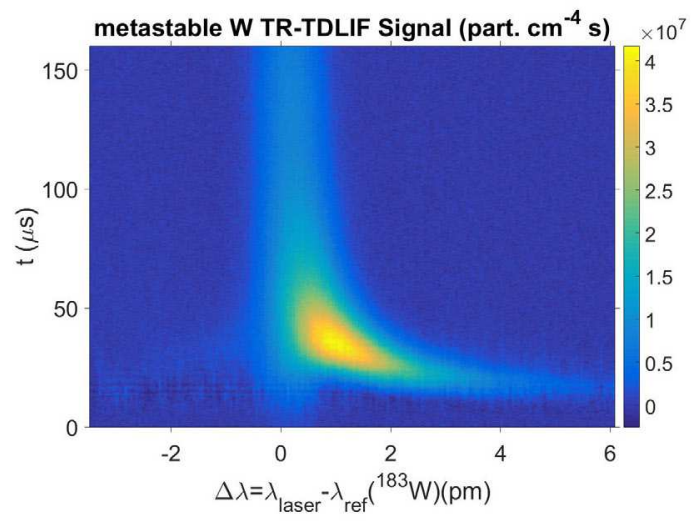

(a)

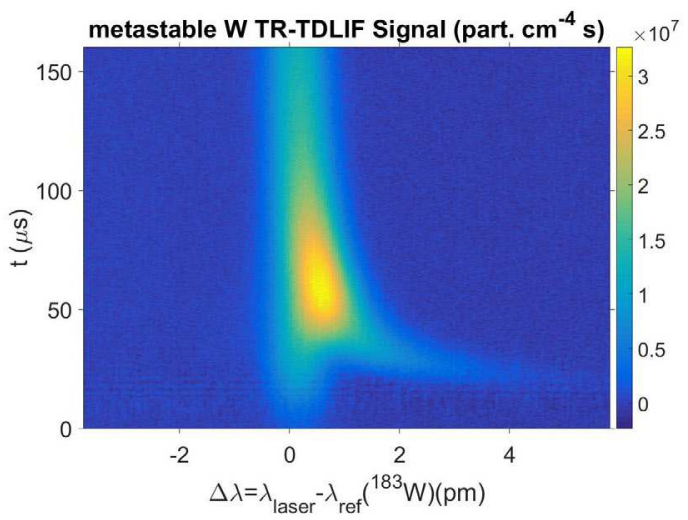

(b)

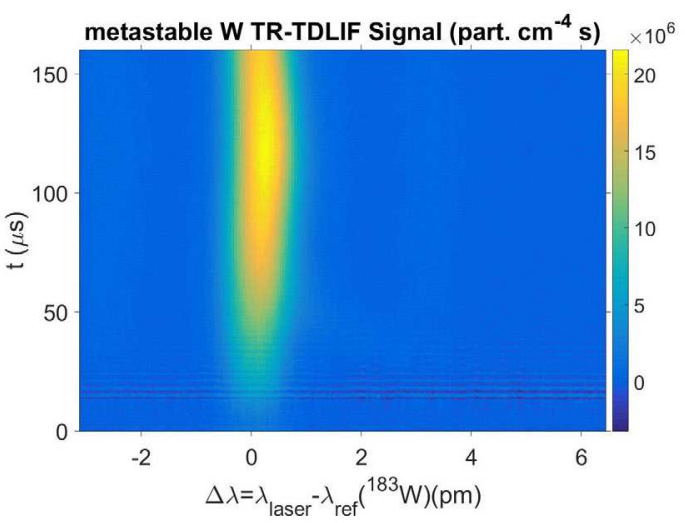

(c)

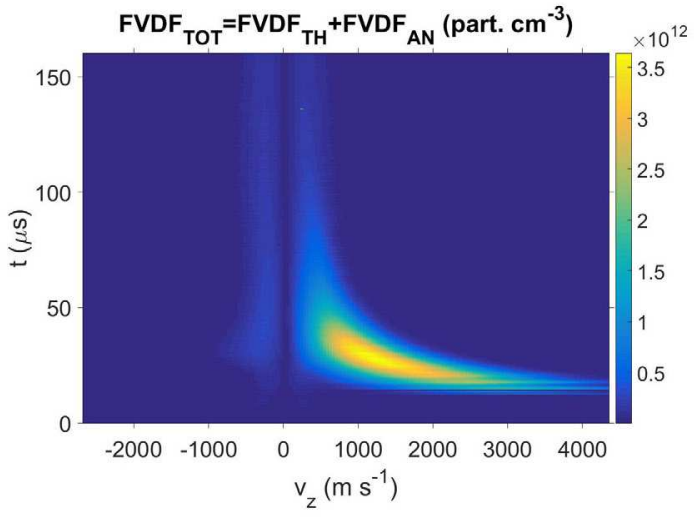

(d)

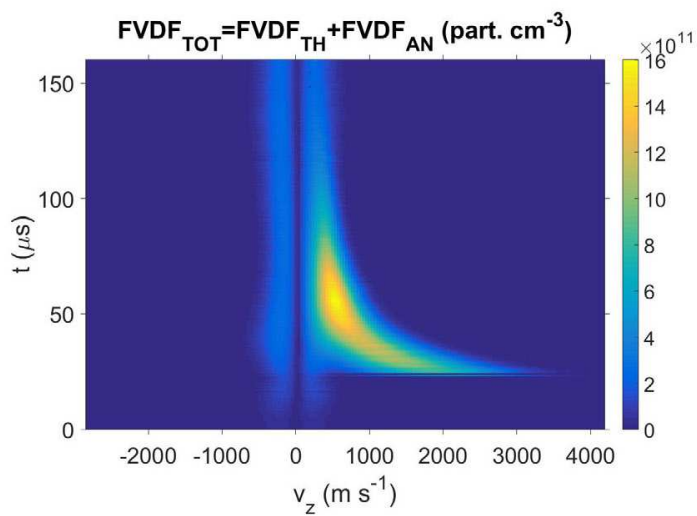

(e)

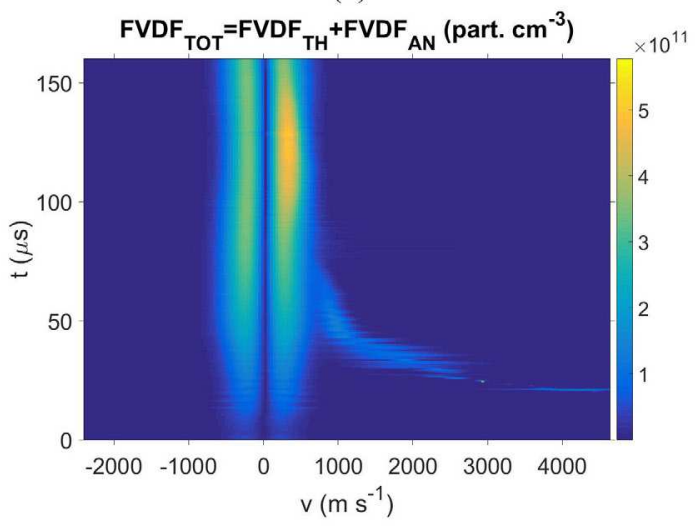

(f)

Figure 6. (a)-(c) Temporal ( $t=0$ to $160 \mu \mathrm{s})$ and spatial $(z=3,5,9 \mathrm{~cm})$ variations of TR-TDLIF signals. (d)-(f) Temporal ( $t=0$ to $160 \mu \mathrm{s})$ and spatial $(z=3,5,9 \mathrm{~cm})$ variations of FVDF. $R_{0}=1.3 \mathrm{~cm} ; p=0.4 \mathrm{~Pa} ; P_{\mathrm{av}}=120 \mathrm{~W}$.

First, at $z=3 \mathrm{~cm}$ (figure 6(a)) where plasma spontaneous emission is not disturbing and it is close to the sputtering source where the measured anisotropic population is significant. Then, at $z=9 \mathrm{~cm}$ (figure 6(c)) where the majority of atoms are thermalized (symmetrical signal) and is typically a distance used in the industry to achieve deposition. At $z=5 \mathrm{~cm}$ as an intermediate case to visualize the transition between those two extreme cases. Figures 6(d)-(f) represent the flux velocity distribution function $\left(\mathrm{FVDF}_{\mathrm{TOT}}\right)$ derived from the evolution of TR-TDLIF signals of figures 6(a)-(c), respectively. As expected, at $z=3 \mathrm{~cm}$ (figure 6(d)), anisotropic atoms flux is dominant compared to the thermalized one due to their high velocities. At $z=5 \mathrm{~cm}$, much less anisotropic atoms are measured (tail of coma shape) which is logical considering the sputtered atoms emission cone ( $70 \%$ of the sputtered vapour is globally emitted in a $\alpha=45^{\circ}$ emission cone with respect to the normal of the target surface) [25]. In fact, the further away the probed volume is from the target, the less likely it is to contain anisotropic W atoms since the section of the sputtered emission cone increases. Unexpectedly, the asymmetrical part of the $\mathrm{FVDF}_{\mathrm{TOT}}$ exhibits two contributions in its temporal evolution (from 10 to $40 \mu$ s and from 40 to 120 $\mu \mathrm{s})$. This is better seen at $z=9 \mathrm{~cm}$ as $\mathrm{FVDF}_{\text {TOT }}$ shows clearly an asymmetrical shape at longer time (around $t=120 \mu \mathrm{s}$ ) 


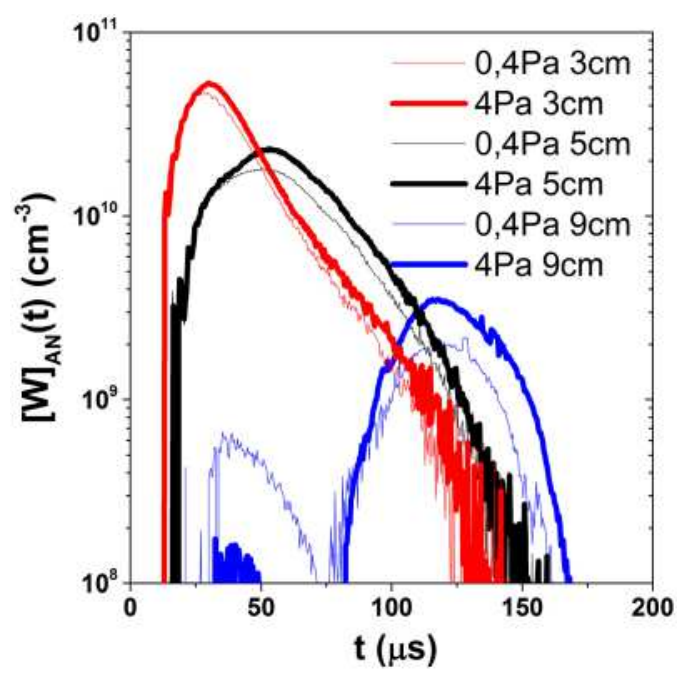

Figure 7. $[\mathrm{W}]_{\mathrm{AN}}(t)$ temporal evolutions at 3,5 and $9 \mathrm{~cm}, P_{\mathrm{av}}=120$ $\mathrm{W}, p=0.4$ (thin lines) and $4 \mathrm{~Pa}$ (thick lines); $R_{0}=1.3 \mathrm{~cm}$.

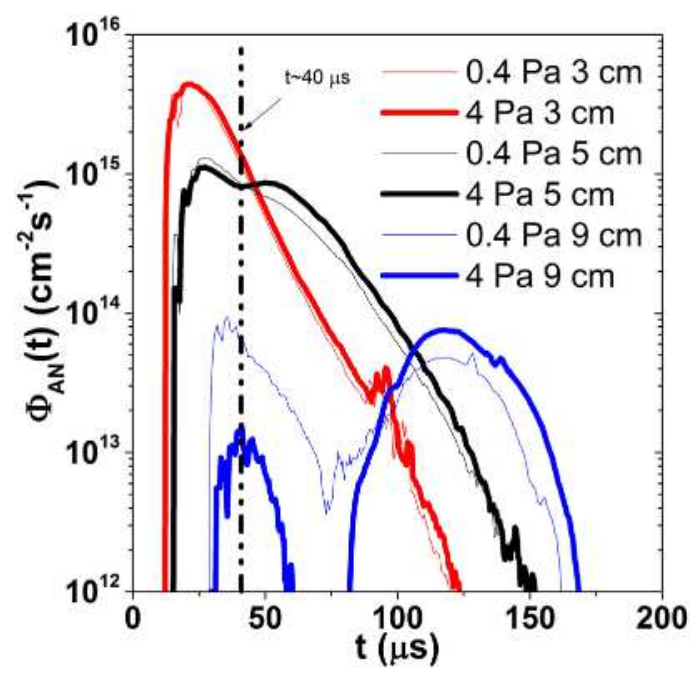

Figure 8. $\Phi_{\mathrm{AN}}(t)$ temporal evolutions at 3,5 et $9 \mathrm{~cm}, P_{\mathrm{av}}=120 \mathrm{~W}$, $p=0.4$ (thin lines) and $4 \mathrm{~Pa}$ (thick lines); $R_{0}=1.3 \mathrm{~cm}$.

than the transport of atoms with high velocities between 10 and $\sim 50 \mu \mathrm{s}$ (energetic atoms). This suggests that there are not only energetic atoms composing the anisotropic part of the distribution and the purpose of the next section is to figure out this second population of anisotropic atoms.

\subsection{Identification of a second population of anisotropic atoms}

Figures 7 and 8 represent the temporal evolution of $[\mathrm{W}]_{\mathrm{AN}}(t)$ for 3 distances $(z=3,5,9 \mathrm{~cm})$ and 2 pressures $(p=0.4$ and $4 \mathrm{~Pa}$ ). Getting further away from the target (at $z=5$ and $9 \mathrm{~cm}$ ), two peaks can be observed on the temporal evolution of densities and fluxes as in previous section with the $2 \mathrm{D}$ representations.

At the longest distance $(z=9 \mathrm{~cm})$, the first peak (between 10 and $\sim 75 \mu \mathrm{s}$ ) decreases while the second peak (between 75 and $170 \mu \mathrm{s})$ increases at the greater pressure $(4 \mathrm{~Pa})$. The first peak is consistent with energetic atoms behaviour as an

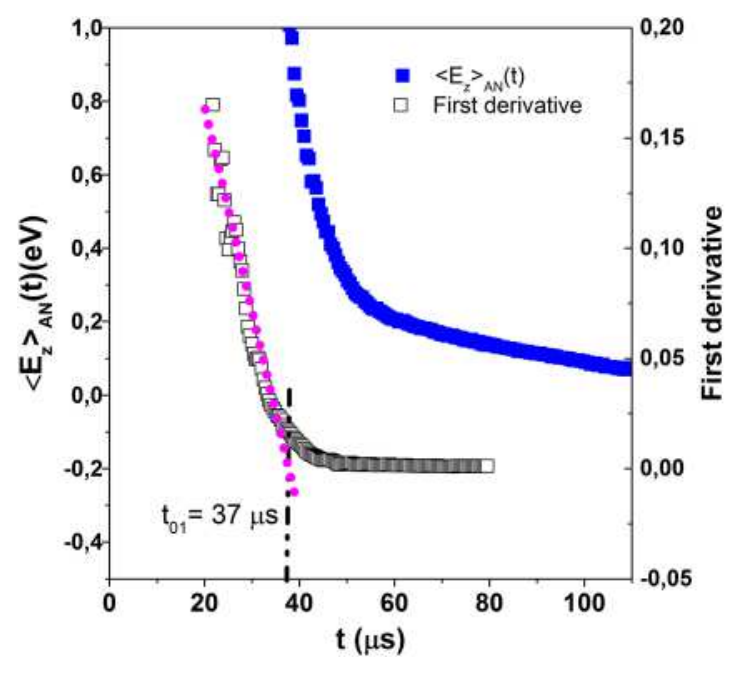

Figure 9. $\left\langle\mathrm{E}_{\mathrm{z}}\right\rangle_{\mathrm{AN}}(t)$ and first derivative temporal evolutions at $z=5 \mathrm{~cm} ; R_{0}=1.3 \mathrm{~cm} ; p=4 \mathrm{~Pa} ; P_{\mathrm{av}}=120 \mathrm{~W}$.

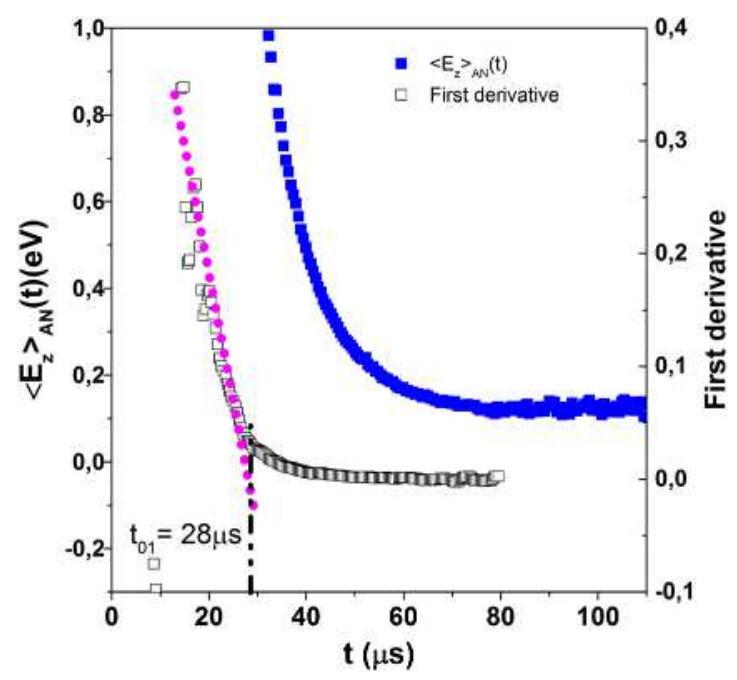

Figure 10. $\left\langle\mathrm{E}_{\mathrm{z}}\right\rangle_{\mathrm{AN}}(t)$ and first derivative temporal evolutions at $z=3 \mathrm{~cm} . R_{0}=1.3 \mathrm{~cm} ; p=4 \mathrm{~Pa} ; P_{\mathrm{av}}=120 \mathrm{~W}$.

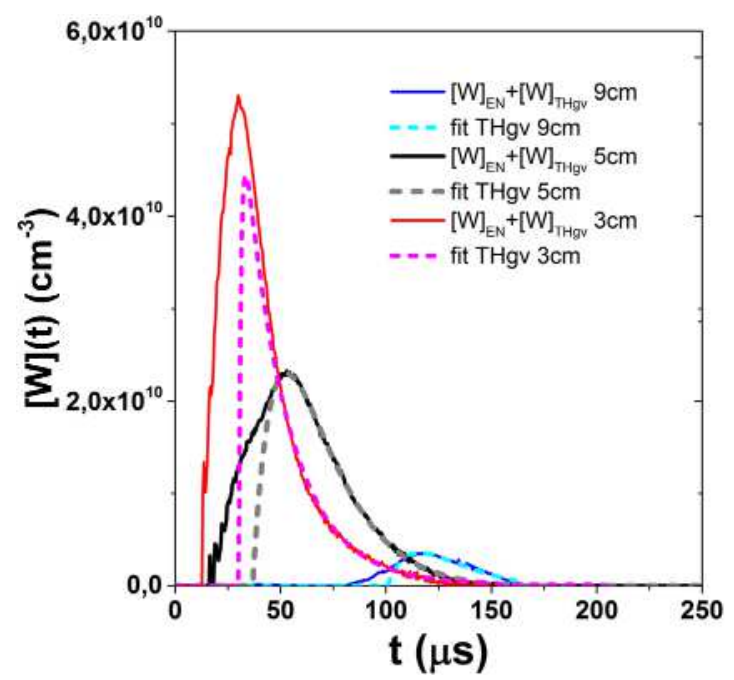

Figure 11. $[\mathrm{W}]_{\mathrm{EN}}(t)+[\mathrm{W}]_{\mathrm{TH}_{\mathrm{gv}}}(t)$ temporal evolutions and $\mathrm{TH}_{\mathrm{gv}}$ theoretical fits at $z=3,5$ and $9 \mathrm{~cm} . R_{0}=1.3 \mathrm{~cm} ; p=4 \mathrm{~Pa} ; P_{\mathrm{av}}=120 \mathrm{~W}$. 


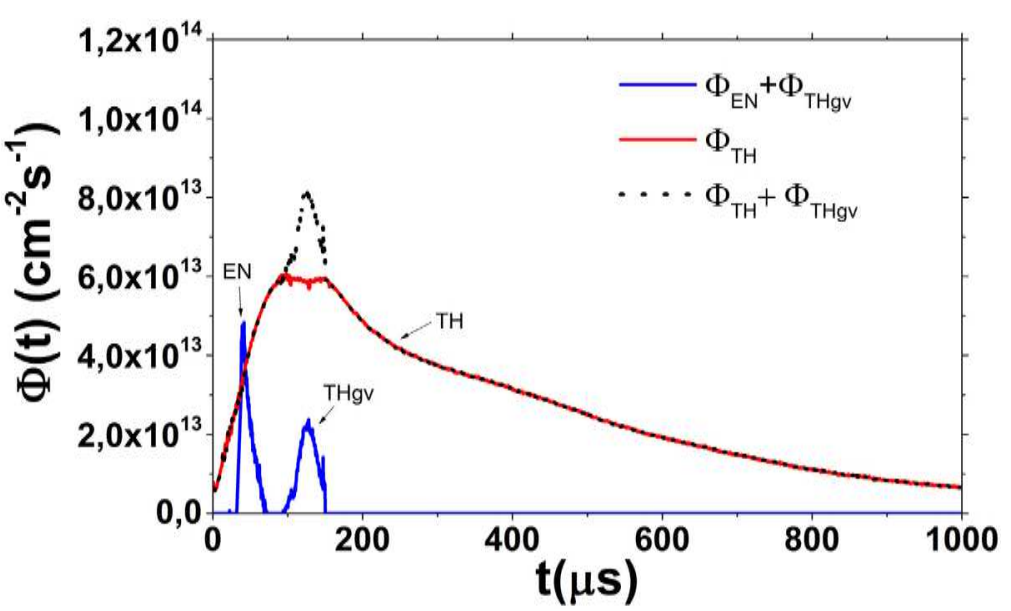

Figure 12. $\Phi_{\mathrm{EN}}(t), \Phi_{\mathrm{THgv}}(t)$ and $\Phi_{\mathrm{TH}}(t)$ temporal evolutions at $z=9 \mathrm{~cm}, P_{\mathrm{av}}=120 \mathrm{~W}, p=4 \mathrm{~Pa} . R_{0}=1.3 \mathrm{~cm}$.

increase of pressure implies a more effective thermalization (better energy transfer due to the increase of the number of collisions) resulting in a decrease of measured energetics. However, the second peak behaviour remains to be clarified. For this purpose, the time evolution of the mean energy $\left\langle E_{z}\right\rangle$ $\operatorname{AN}(t)$ (equation (5)) was calculated in the case of $z=5 \mathrm{~cm}$ and $p=4 \mathrm{~Pa}$ (figure 9) where the second peak is clearly visible (after $t \sim 40 \mu \mathrm{s}$ ). $\left\langle\mathrm{E}_{\mathrm{z}}\right\rangle_{\mathrm{EN}}$ of the energetic metastable atoms moving away from the target is given by: $\left\langle\mathrm{E}_{\mathrm{z}}\right\rangle_{\mathrm{EN}}=0.5 \mathrm{M}\left\langle\mathrm{v}_{\mathrm{z}}^{2}\right\rangle$ with $\left\langle v_{z}^{2}\right\rangle$ given by equation (5).

$$
\left\langle v_{\mathrm{z}}^{2}\right\rangle=\frac{\int_{0}^{+\infty} \mathrm{v}_{\mathrm{z}}^{2} \operatorname{AVDFdv}_{\mathrm{z}}}{\int_{0}^{+\infty} \operatorname{AVDFdv}_{\mathrm{z}}}
$$

It exhibits a fast variation during the period of time corresponding to the first peak $\left(\left\langle\mathrm{E}_{\mathrm{z}}\right\rangle_{\mathrm{AN}}(t)\right.$ is between $10 \mathrm{eV}$ and $0.6 \mathrm{eV})$, which is characteristic of fast energetic atoms crossing the probed volume. A significant change is noticed at $t=37 \mu$ s coinciding with the apparition of the second peak and arrival of the second anisotropic population of atoms. The latter $\left\langle\mathrm{E}_{\mathrm{z}}\right\rangle_{\mathrm{AN}}(t)$ range is $0.6-0.05 \mathrm{eV}$ which is close to thermalized atoms energy. The assumption of thermalized atoms with a group velocity was then made as their properties are close to isotropic (around $v_{z}=0$ ) thermalized ones. Indeed, they are probably atoms that have not completed their thermalization process which are missing one or two collisions to reach a complete isotropic velocity distribution function. This means that this population of atoms has an intermediate regime of transport between ballistic and diffusive, closer to the latter. That is why this population is named ' $\mathrm{TH}_{\mathrm{gv}}$ ' for thermalized atoms $(\mathrm{TH})$ with a group velocity (gv) moving away from the target.

In order to distinguish energetic (EN) and $\mathrm{TH}_{\mathrm{gv}}$ populations, a procedure was adopted consisting in calculating $\left\langle E_{z}\right\rangle$ AN $(t)$ first derivative. This gives an approximation of the arrival time $t_{01}$ of $\mathrm{TH}_{\mathrm{gv}}$ in the probed volume. Knowing $t_{01}$, $\mathrm{TH}_{\mathrm{gv}}$ population best fit with exponential functions (given by equation (6)) which proves that the source and loss terms are linear.

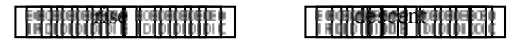

$[\mathrm{W}]_{\mathrm{TH}_{\mathrm{gv}}}(\mathbb{t})=\mathrm{A}\left[1-\mathrm{e}^{-\mathrm{C}_{\mathrm{p} 1}\left(\mathrm{t}^{\left.-\mathrm{t}_{01}\right)}\right.}\right]$ or $\mathrm{A}\left[\mathrm{e} \quad \mathrm{e}^{-\mathrm{C}_{\mathrm{p} 2}\left(\mathbb{t}-\mathrm{t}_{02}\right)}\right.$.

with $\mathrm{A}\left(1-\mathrm{e}^{\left.-\mathrm{C}_{\mathrm{p} 1} \mathrm{t}_{02}-\mathrm{t}_{01}\right)}\right)$ being the $T \mathrm{~h}_{\mathrm{gv}}$ maximum value at $t=t_{02}, C_{p 1}$ the rise loss coefficient, $C_{p 2}$ the descent loss coefficient, $t_{01}$ and $t_{02}$ are 'rise' and 'descent' functions initial times, respectively. $C_{p 1}$ and $C_{p 2}$ may be different cause of temperature variation during $\mathrm{Th}_{\mathrm{gv}}$ cross time lapse. In a simple case $(z \geqslant 5 \mathrm{~cm})$, it is possible to easily distinguish the anisotropic population of atoms and consequently to extract from the total curve the part corresponding to $\mathrm{TH}_{\mathrm{gv}}$ atoms. However, in a more complicated situation as at $z=3 \mathrm{~cm}$, there is likely $\mathrm{TH}_{\mathrm{gv}}$ in relatively low quantity and strongly convoluted with a high density of EN atoms.

Figure 10 gives $\left\langle\mathrm{E}_{\mathrm{z}}\right\rangle_{\mathrm{AN}}(t)$ variation and the corresponding first derivative at $z=3 \mathrm{~cm}, P_{\mathrm{av}}=120 \mathrm{~W}, p=4 \mathrm{~Pa}$. $t_{01}$ corresponds to the time the first derivative changes of curvature and gets close to zero. Indeed, $t_{01} \sim 37 \mu$ s in figure 9 coincides with arrival of $\mathrm{TH}_{\mathrm{gv}}$ on figure 8 (black curves). This validates the method of distinguishing both $\mathrm{EN}$ and $\mathrm{TH}_{\mathrm{gv}}$ populations which determines $t_{01}=28 \mu \mathrm{s}$ at $z=3 \mathrm{~cm}$ according to figure $10\left(t_{02}\right.$ is a free parameter of the fit, as $\left.A, C_{p 1}, C_{p 2}\right)$. With this procedure, an example of fit is shown in figure 11 where $\mathrm{TH}_{\mathrm{gv}}$ atoms are estimated by fitting the curve with the function given in equation (5). EN population is then estimated subtracting $\mathrm{Th}_{\mathrm{gv}}$ fitting curve.

\section{3. $T H_{g v}$ population properties}

The $\mathrm{TH}_{\mathrm{gv}}$ group velocity $\left(\mathrm{gv} \sim 750 \mathrm{~ms}^{-1}\right.$ ) calculated using the characteristic $\mathrm{TH}_{\mathrm{gv}}$ maxima times $t_{02}$ (densities and fluxes, figures 7 and 8, respectively) is distance and pressure independent. This means that $\mathrm{Th}_{\mathrm{gv}}$ transport is weakly influenced by the collision conditions as it exhibits just more or less losses (destruction) and the transport properties up to the probed volume seem to be conserved. Moreover, as observed in figure 12 representing the time evolutions of $\Phi_{\mathrm{EN}}(t)$, $\Phi_{\mathrm{TH}}(t)$ and $\Phi_{\mathrm{THgv}}(t)$ at $z=9 \mathrm{~cm}\left(p=4 \mathrm{~Pa}, P_{\mathrm{av}}=120 \mathrm{~W}\right)$, 


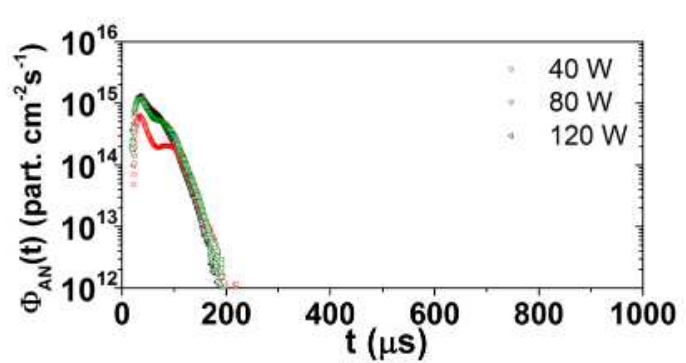

(a.1)

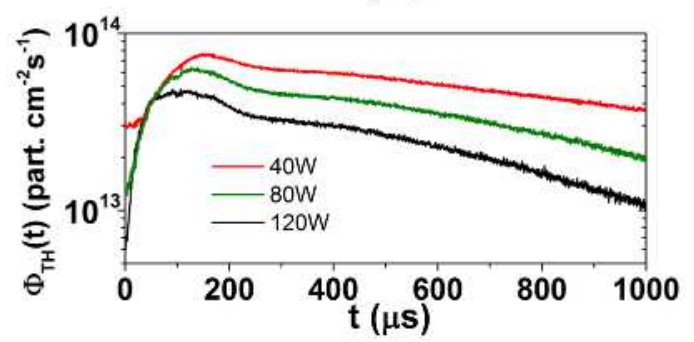

(a.2)

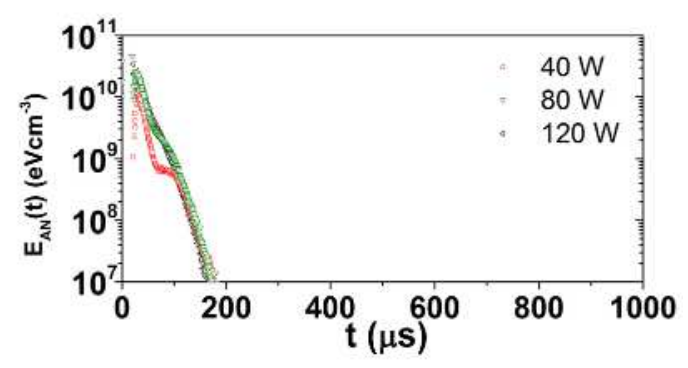

(b.1)

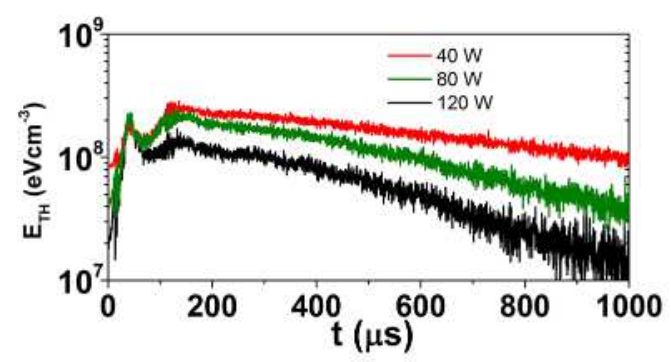

(b.2)

Figure 13. Temporal evolutions of deposited flux ((a.1) and (a.2)) and energy ((b.1) and (b.2)) of anisotropic $\left(\mathrm{EN}+\mathrm{TH}_{\mathrm{gv}}\right)$ and isotropic atoms $(\mathrm{TH})$ for three $P_{\mathrm{av}}(40 \mathrm{~W}, 80 \mathrm{~W}, 120 \mathrm{~W})$ at $z=5 \mathrm{~cm}$; $R_{0}=1.3 \mathrm{~cm} ; p=0.4 \mathrm{~Pa}$.

the characteristic $\mathrm{TH}_{\mathrm{gv}}$ maximum time happens at the same time as thermalized one. The observable missing part of the maximum of $\mathrm{TH}$ atoms can be completed by $\mathrm{TH}_{\mathrm{gv}}$. This link between $\mathrm{TH}_{\mathrm{gv}}$ and $\mathrm{TH}$ is logical as first thermalized atoms are $\mathrm{Th}_{\mathrm{vg}}$ that has just undergone one or two additional collisions to become isotropic atoms $\left(\mathrm{Th}_{\mathrm{gv}}\right.$ destruction supplies thermalized population). Nevertheless, the fact that those characteristic times are independent from collision conditions is surprising. In fact, $\mathrm{TH}_{\mathrm{gv}}$ detected in the probed volume (and first thermalized) are sputtered atoms that have undergone the same number of collisions with Ar atoms whatever the distance $(\operatorname{sog} \operatorname{gv}(z) \approx$ constant $)$ or the pressure.

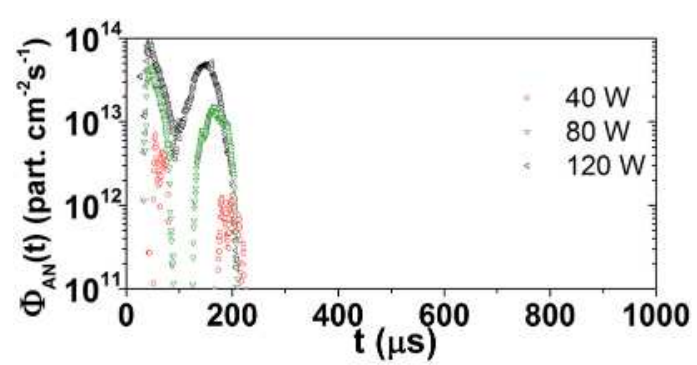

(a.1)

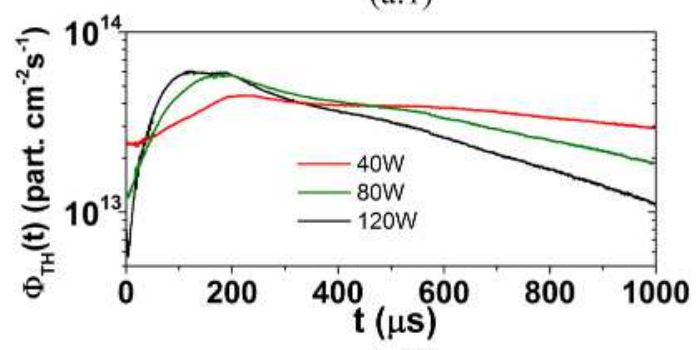

(a.2)

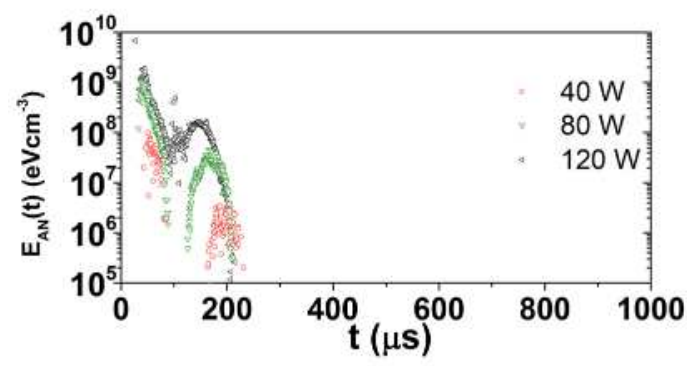

(b.1)

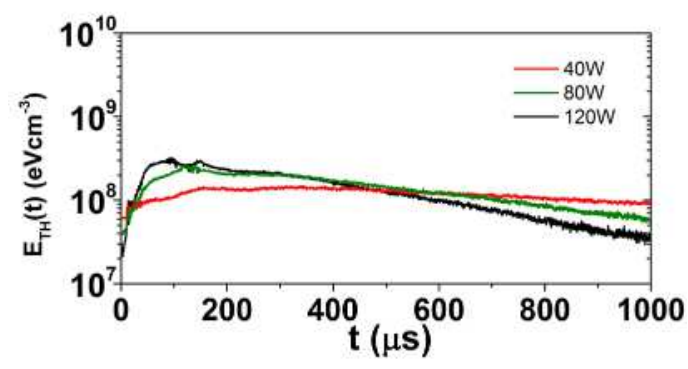

(b.2)

Figure 14. Temporal evolutions of deposited flux ((a.1) and (a.2)) and energy ((b.1) and (b.2)) of anisotropic $\left(\mathrm{EN}+\mathrm{TH}_{\mathrm{gv}}\right)$ and isotropic atoms (TH) for three $P_{\mathrm{av}}(40 \mathrm{~W}, 80 \mathrm{~W}, 120 \mathrm{~W})$ at $z=9 \mathrm{~cm}$; $R_{0}=1.3 \mathrm{~cm} ; p=0.4 \mathrm{~Pa}$.

The collision conditions influence the number of detected $\mathrm{TH}_{\mathrm{gv}}$ atoms (and of course the amplitude of the maxima) but weakly influence the transport velocity. Note that those results could be highlighted because $\mathrm{W}$ atoms are heavy (by comparison with Ar atoms) and keep transport properties in terms of velocity (around gv) and direction even after undergoing several collisions with buffer gas atoms until they are completely thermalized (around $v_{z}=0$ ). To sum up, EN are atoms that have undergone none or a few collisions, quasithermalized $\left(\mathrm{TH}_{\mathrm{gv}}\right)$ about $8-10$ collisions, $\mathrm{TH}$ atoms more than 10 collisions. Three intervals of time characterised by different regimes of transport can then be determined. Balistic transport $(\sim 10-50 \mu \mathrm{s})$ corresponding to $\mathrm{EN}$ atoms, quasi-diffusive 


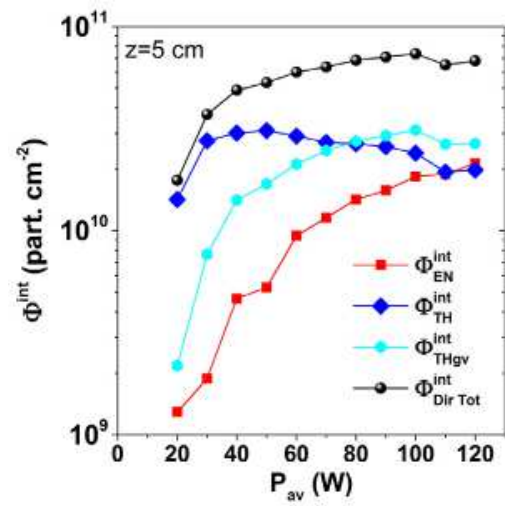

(a.1)

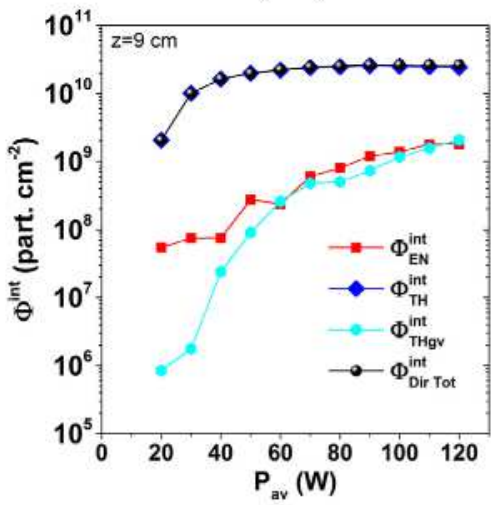

(a.2)

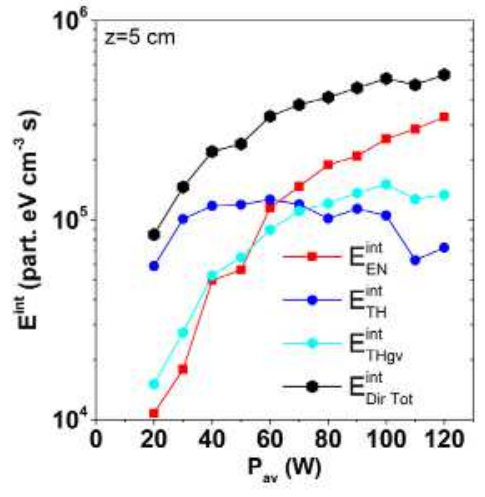

(b.1)

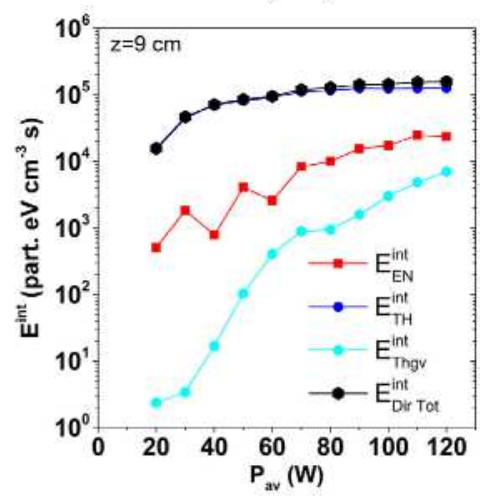

(b.2)

Figure 15. Total deposited fluxes $\left(\Phi \underset{\mathrm{EN}}{\mathrm{int}}, \Phi_{\mathrm{TH}_{\mathrm{gv}}}^{\mathrm{int}}, \Phi_{\mathrm{TH}}^{\mathrm{int}}, \Phi_{\text {Dir Tot }}^{\mathrm{int}}\right)\left((\mathrm{a} .1)\right.$ and (a.2)) and total deposited energies $\left(\mathrm{E}_{\mathrm{EN}}^{\mathrm{int}}, \mathrm{E}_{\mathrm{TH}}^{\mathrm{int}} \mathrm{Ev}_{\mathrm{TH}}^{\mathrm{int}}, \mathrm{E}_{\mathrm{Dir} \mathrm{Tot}}^{\mathrm{int}}\right)$ ((b.1) and (b.2)) of EN, $\mathrm{TH}_{\mathrm{gv}}$ and $\mathrm{TH}$ at $z=5$ and $9 \mathrm{~cm} . R_{0}=1.3 \mathrm{~cm} ; p=0.4 \mathrm{~Pa}$.

$(\sim 50-200 \mu \mathrm{s})$ for $\mathrm{TH}_{\mathrm{gv}}$ atoms, and diffusive $(\sim 50 \mu \mathrm{s}$-end of post-discharge $=1 \mathrm{~ms}$ ) for $\mathrm{TH}$ atoms.

\section{Deposited flux and energy per population}

Having now the ability to dissociate three populations of atoms that are energetic (EN), quasi-thermalized $\left(\mathrm{TH}_{\mathrm{vg}}\right)$ and thermalized (TH) atom, deposited flux $\Phi(t)$ and energy $E(t)$ (equation (7)) directed toward the substrate can be determined for each one of them.

$$
\mathrm{E}(\mathbb{t})=0.5 \mathrm{M} \int_{0}^{+\infty} \mathrm{v}_{\mathrm{z}}^{2} \operatorname{AVDF}\left(\mathrm{v}_{\mathrm{z}}, \mathrm{t}\right) \mathrm{dv}_{\mathrm{z}}
$$

More specifically it allows to obtain the whole behaviour of deposited atoms properties along a HiPIMS period under varying parameters. In this part, a whole characterisation of those properties is presented for two distances $(z=5$ and $9 \mathrm{~cm})$, one pressure $(0.4 \mathrm{~Pa})$, varying $P_{\mathrm{av}}$ from 20 to $120 \mathrm{~W}$.

Figures 13 and 14 represent the time evolutions of deposited flux $\Phi(t)$ ((a.1) et (a.2)) and energy $E(t)$ ((b.1) et (b.2)) of anisotropic (AN) and isotropic (TH) atoms at $z=5$ and $9 \mathrm{~cm}$, respectively. Both parameters vary significantly with $P_{\mathrm{av}}$ and the distance $z$. As expected, the increase of $P_{\mathrm{av}}$ results in more anisotropic atoms measured at $z=5$ (figure 13(a.1)) and $9 \mathrm{~cm}$ (figure 14(a.1)) due to a more intense target sputtering. Indeed, the increase of $P_{\mathrm{av}}$ implies an increase of discharge voltage (energy of incident ions) and current (number of incident ions), see figure 16. Nevertheless, TH atoms show a more complicated behaviour with several slopes in their time evolution. This may be due to a combination of events such as the thermalisation, thermal effects causing heating (dilatation) or cooling (contraction) of the buffer gas, sputtering wind (sputtered atoms blowing away the buffer gas atoms reducing its local density), losses by collisions and so on ... No further explanations are given as modelling will be necessary in those complicated cases.

The deposited $\Phi_{\mathrm{AN}}(t)$ and $E_{\mathrm{AN}}(t)$ occur within the first $200 \mu \mathrm{s}$ and are more important than $\Phi_{\mathrm{TH}}(t)$ which are deposited during the whole HiPIMS period. It means that AN may interact shortly with the substrate. Consequently, it is crucial to determine the contribution of each population in terms of total deposited energy and flux.

The fraction of total deposited flux and energy for each population is determined by calculating $\Phi$ int (equation (9)), $\Phi{ }_{\mathrm{EN}}^{\mathrm{int}} \mathrm{gv}_{\mathrm{gv}}$ (equation (10)), $\Phi_{\mathrm{TH}}^{\mathrm{int}}$, $\Phi_{\text {Dir Tot }}^{\mathrm{int}}$ and $\mathrm{E}_{\mathrm{EN}}^{\mathrm{int}}$ (equation (11)), $\mathrm{E}_{\mathrm{TH}}^{\mathrm{int}}$ (equation (12)), $\mathrm{E}_{\mathrm{TH}}^{\mathrm{int}}$ (equation (13)), $\mathrm{E}_{\mathrm{Dir} \text { Tot }}^{\mathrm{int}}$ (equation (14)).

$$
\begin{gathered}
\Phi_{\mathrm{AN}}^{\mathrm{int}}=\Phi_{\mathrm{EN}}^{\mathrm{int}}+\Phi_{\mathrm{TH}_{\mathrm{gv}}}^{\mathrm{int}} \\
\Phi_{\mathrm{EN}}^{\mathrm{int}}=\int_{t=0}^{t_{01}} \Phi_{\mathrm{EN}}(t) \mathrm{dt} \\
\Phi_{\mathrm{TH} \mathrm{gv}_{\mathrm{gv}}}^{\text {int }}=\int_{t_{01}}^{\mathrm{t}=1 \mathrm{~ms}} \Phi_{\mathrm{TH}_{\mathrm{vg}}}(t) \mathrm{d} t
\end{gathered}
$$




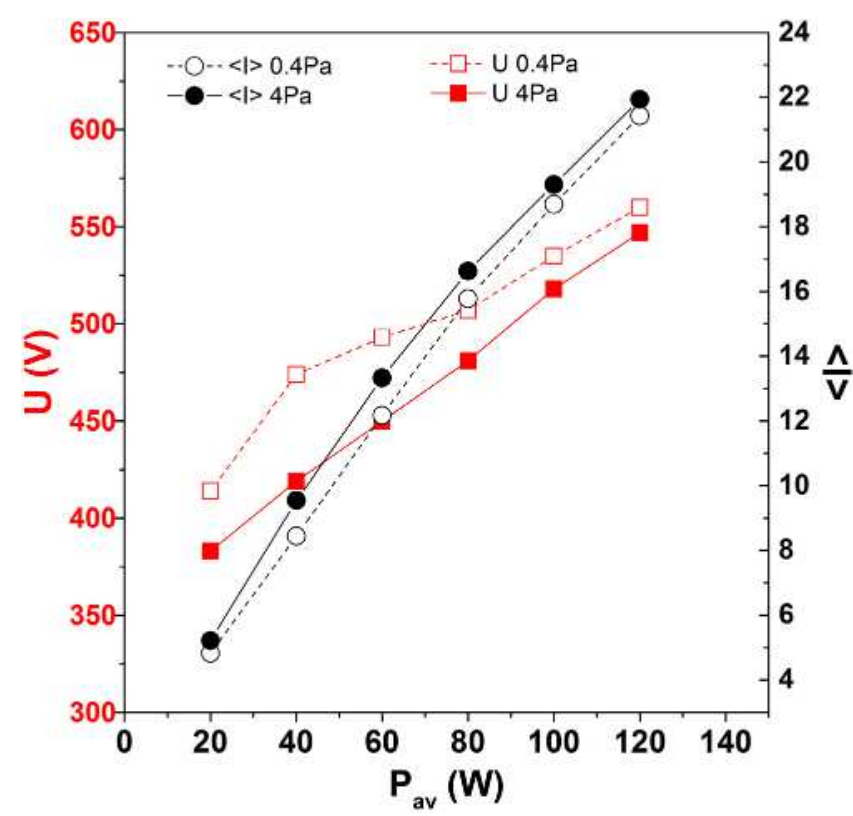

Figure 16. Variation of HiPIMS discharge voltage $(U)$ and current $(\langle\mathrm{I}\rangle)$ as function of $P_{\mathrm{av}}$, at $p=0.4$ and $4 \mathrm{~Pa}$.

$$
\begin{aligned}
& \mathrm{E}_{\mathrm{EN}}^{\mathrm{int}}=\int_{\mathrm{t}=0}^{\mathrm{t}_{01}} \mathrm{E}_{\mathrm{EN}}(t) \mathrm{dt} \\
& \mathrm{E}_{\mathrm{TH}_{\mathrm{gv}}}^{\mathrm{int}}=\int_{\mathrm{t}_{01}}^{\mathrm{t}=1 \mathrm{~ms}} \mathrm{E}_{\mathrm{Th}_{\mathrm{gv}}}(\mathrm{t}) \mathrm{dt} \\
& E_{\mathrm{TH}}^{\mathrm{int}}=\int_{\mathrm{t}=0}^{\mathrm{t}=1 \mathrm{~ms}} \mathrm{E}_{\mathrm{TH}}(\mathbb{t}) \mathrm{dt} \\
& \mathrm{E}_{\mathrm{Dir} T o t}^{\mathrm{int}}=\mathrm{E}_{\mathrm{EN}}^{\mathrm{int}}+\mathrm{E}_{\mathrm{Th}}^{\mathrm{int}}+\mathrm{E}_{\mathrm{TH}}^{\mathrm{int}}
\end{aligned}
$$

As shown in figure 15 , at $z=5 \mathrm{~cm}$, globally the increase of $P_{\text {av }}$ implies an increase of deposited flux $\left(\Phi_{\operatorname{Dir} \text { Tot }}^{\mathrm{int}}\right)$ and energy ( $\mathrm{E}_{\text {DirTot }}^{\mathrm{int}}$ ) but it's mainly due to $\mathrm{EN}$ and $\mathrm{TH}_{\mathrm{gv}}$ populations since $\Phi_{\mathrm{TH}}^{\mathrm{int}}$ and $\mathrm{E}_{\mathrm{TH}}^{\mathrm{int}}$ decrease. At low power $\left(20 \mathrm{~W} \leqslant P_{\mathrm{av}} \leqslant 60 \mathrm{~W}\right)$ the majority of deposited flux and energy comes from $\mathrm{TH}$ atoms. At high power $\left(80 \mathrm{~W} \leqslant P_{\mathrm{av}} \leqslant 120 \mathrm{~W}\right)$ fluxes between the three population are quite balanced but the biggest part of deposited energy comes first from $\mathrm{EN}$, then $\mathrm{TH}_{\mathrm{gv}}$ and finally $\mathrm{TH}$ population. The need of discerning $\mathrm{EN}$ and $\mathrm{TH}_{\mathrm{gv}}$ in the anisotropic population is clearly shown here as deposed flux from $\mathrm{TH}_{\mathrm{gv}}$ is bigger than the one of $\mathrm{EN}$ (for all powers) which does not reflect deposited energy as the one from $\mathrm{EN}$ is bigger for $P_{\mathrm{av}}>60 \mathrm{~W}$. The situation completely changes at $z=9 \mathrm{~cm}$ as most of deposited flux and energy comes from TH atoms. Thus, the latter govern neutral particles deposited properties and exhibit a saturation when $P_{\mathrm{av}}$ increases. Indeed, an increase of $300 \%$ on $P_{\mathrm{av}}$ implies only an increase of $\Phi$ int $\operatorname{ir}$ Tot $20 \%$. Thus, between $z=5$ and $9 \mathrm{~cm}$, deposited atoms properties change rapidly which justifies the importance of such measurements in the view of thin layer deposition optimization.

The influence of the discharge voltage (figure 16) and current on the variation of $\left\langle\mathrm{E}_{\mathrm{z}}\right)^{\text {int }}\left(E^{\mathrm{int}} /[\mathrm{W}]^{\mathrm{int}}\right)$ ([W] $]^{\text {int }}$ being the integral of population densities over a HiPIMS period) for each

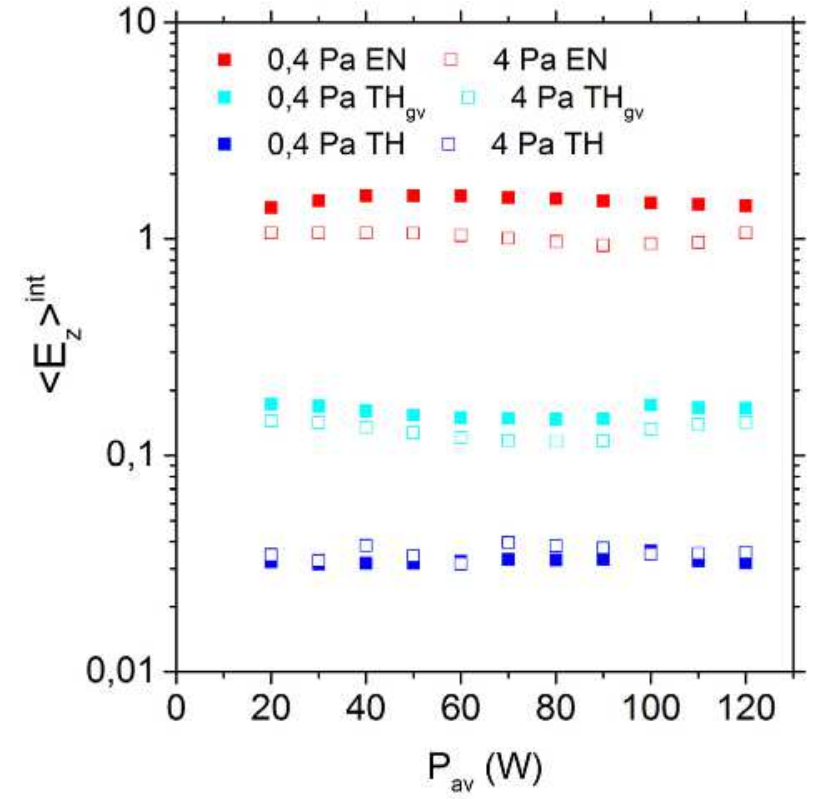

Figure 17. Variation of $\left\langle\mathrm{E}_{\mathrm{z}}\right\rangle^{\text {int }}$ for $\mathrm{EN}, \mathrm{TH}_{\mathrm{gv}}, \mathrm{TH}$ populations measured at $z=5 \mathrm{~cm} ; R_{0}=1.3 \mathrm{~cm} ; p=0.4$ and $4 \mathrm{~Pa}$.

population is now investigated at $z=5 \mathrm{~cm}, p=0.4$ and $4 \mathrm{~Pa}$ and represented in figure 17. It is clear that the voltage does not influence $\left\langle E_{z}\right\rangle^{\text {int }}$ even with a variation of discharge voltage of $\sim 150 \mathrm{~V}\left(P_{\mathrm{av}}=20-120 \mathrm{~W}\right)$. This means that varying $P_{\mathrm{av}}$, only the current is the determinant parameter as it fixes the amount of sputtered material. The values of $\left\langle\mathrm{E}_{\mathrm{z}}\right)^{\mathrm{av}}(\sim 1 \mathrm{eV}$ for $\mathrm{EN}, \sim 0.1$ for $\mathrm{TH}_{\mathrm{gv}}$ and $\sim 0.03 \mathrm{eV}$ for $\mathrm{TH}$ ) confirm that the belonging of atoms to one population depends essentially on the number of collisions they underwent in their ways to the probed volume which determines their energy. This can be seen at a higher pressure $(p=4 \mathrm{~Pa})$ as $\left\langle\mathrm{E}_{\mathrm{z}}\right\rangle^{\text {int }}$ of $\mathrm{AN}$ atoms is a little bit lower.

\section{Conclusion}

In this work a TR-TDLIF (time resolved-tunable diode laser induced fluorescence) technique combining spatial $\left(\sim 3 \mathrm{~mm}^{3}\right)$, temporal $(\sim 0.5 \mu \mathrm{s})$ and spectral $(<0.1 \mathrm{pm})$ resolutions was used to measure the AVDF (atom velocity distribution function), FVDF (flux velocity distribution function) and to study the transport of heavy $\mathrm{W}$ atoms. By varying the discharge parameters (average magnetron power, pressure and distance from target) it becomes possible to obtain the whole scheme of the different stages of transport of sputtered atoms characterized by three intervals of time with different regimes of transport. Balistic transport $(\sim 10-50 \mu \mathrm{s})$ corresponding to energetic atoms (EN: few or no collisions), quasi-diffusive ( $\sim 50-200 \mu \mathrm{s})$ for quasi-thermalized atoms ( $\mathrm{TH}_{\mathrm{gv}}: 8-10$ collisions), diffusive $(\sim 50 \mu$ s-end of post-discharge $=1 \mathrm{~ms})$ for thermalized atoms (TH: $>10$ collisions). The ability to distinguish these three populations of atoms give access to a better understanding of fundamental aspects of transport through $\mathrm{TH}_{\mathrm{gv}}$ properties. Moreover, a direct characterisation of deposited atom properties in term of flux and energy is accessible at distances typically 
used in the industry $(z=5$ and $9 \mathrm{~cm})$ in view of a potential tunablelity of thin film properties. Results indicate that deposed atom properties are dominated by anisotropic atoms at $z=5 \mathrm{~cm}$ while dominated by thermalized ones at $z=9 \mathrm{~cm}$. Spatial and temporal characterization of the energy and flux of deposited species could be exploited to tune thin film physical properties (morphology, rugosity, crystallinity, density or porosity, etc). Aside the potential applications in thin film deposition, there are also important ones in the field of modelling. Magnetron plasma modelling is complicated because of the magnetic and electric field configurations, particles and plasma-wall interactions. The measured atoms velocity distribution function can be injected in modelling code for plasma description. Most of models are either about the plasma or the particle transport but the effect of the sputtered vapour on the plasma is often not taken into account. Consequently, in order to validate the models, experimental data as those provided in the article can be exploited. Also, those data can be used in the determination of the collision cross sections $\mathrm{Ar} / \mathrm{W}$ as the theory on low energy range should be adjusted (which was achieved on Ti [8] but remain to be done in the case of W).

\section{Acknowledgments}

This work was supported by the European Community under the contract of Association between EURATOM and CEA. Financial support was also provided by the Fonds Européen de Développement Régional through the I3P-ITER project.

\section{References}

[1] Sarakinos K, Alami J and Konstantinidis S 2010 High power pulsed magnetron sputtering: a review on scientific and engineering state of the art Surf. Coat. Technol. 204 1661-84

[2] Samuelsson M, Lundin D, Jensen J, Raadu M A, Gudmundsson J T and Helmersson U 2010 On the film density using high power impulse magnetron sputtering Surf. Coat. Technol. 205 591-6

[3] Thornton J A 1974 Influence of apparatus geometry and deposition conditions on the structure and topography of thick sputtered coatings J. Vac. Sci. Technol. 11 666-70

[4] Kersten H, Deutsch H, Steffen H, Kroesen G M W and Hippler R 2001 The energy balance at substrate surfaces during plasma processing Vacuum 63 385-431

[5] Petrov I, Adibi F, Greene J E, Hultman L and Sundgren J E 1993 Average energy deposited per atom: a universal parameter for describing ion-assisted film growth? Appl. Phys. Lett. 63 36-8

[6] Somekh R E 1984 The thermalization of energetic atoms during the sputtering process J. Vac. Sci. Technol. A 2 1285-91

[7] Britun N, Minea T, Konstantinidis S and Snyders R 2014 Plasma diagnostics for understanding the plasma-surface interaction in HiPIMS discharges: a review J. Phys. D: Appl. Phys. 47224001

[8] Lundin D, Vitelaru C, de Poucques L, Brenning N and Minea T 2013 Ti-Ar scattering cross sections by direct comparison of Monte Carlo simulations and laser-induced fluorescence spectroscopy in magnetron discharges $J$. Phys D: Appl. Phys. 46175201
[9] Macák K, Kouznetsov V, Schneider J, Helmersson U and Petrov I 2000 Ionized sputter deposition using an extremely high plasma density pulsed magnetron discharge J. Vac. Sci. Technol. A 18 1533-7

[10] Gudmundsson J T, Alami J and Helmersson U 2002 Spatial and temporal behavior of the plasma parameters in a pulsed magnetron discharge Surf. Coat. Technol. 161 249-56

[11] Wolter M, Do H T, Steffen H and Hippler R 2005 Aluminium atom density and temperature in a dc magnetron discharge determined by means of blue diode laser absorption spectroscopy J. Phys. D: Appl. Phys. 382390

[12] Vitelaru C, Minea T, De Poucques L, Ganciu M and Popa G 2011 Time resolved tunable diode laser absorption spectroscopy on $\mathrm{Al}$ and $\mathrm{Ar}^{\mathrm{M}}$ atoms in high power impulse magnetron sputtering Rom. J. Phys. 56 47-53

[13] Vitelaru C, Aniculaesei C, de Poucques L, Minea T M, Boisse-Laporte C, Bretagne J and Popa G 2010 Tunable diode-laser induced fluorescence on $\mathrm{Al}$ and $\mathrm{Ti}$ atoms in low pressure magnetron discharges J. Phys. D: Appl. Phys. 43124013

[14] Vitelaru C, de Poucques L, Minea T M and Popa G 2011 Space-resolved velocity and flux distributions of sputtered Ti atoms in a planar circular magnetron discharge Plasma Sources Sci. Technol. 20045020

[15] Vitelaru C, de Poucques L, Minea T M and Popa G 2011 Time resolved metal line profile by near-ultraviolet tunable diode laser absorption spectroscopy J. Appl. Phys. 109053307

[16] De Poucques L, Imbert J C, Boisse-Laporte C, Bretagne J, Ganciu M, Teulé-Gay L and Touzeau M 2006 Study of the transport of titanium neutrals and ions in the post-discharge of a high power pulsed magnetron sputtering device Plasma Sources Sci. Technol. 15661

[17] De Poucques L, Vitelaru C, Minea T M, Bretagne J and Popa G 2008 On the anisotropy and thermalization of the metal sputtered atoms in a low-pressure magnetron discharge Europhys. Lett. 8215002

[18] Sushkov V, Do H T, Cada M, Hubicka Z and Hippler R 2013 Time-resolved tunable diode laser absorption spectroscopy of excited argon and ground-state titanium atoms in pulsed magnetron discharges Plasma Sources Sci. Technol. 22015002

[19] Desecures M, de Poucques L and Bougdira J 2015 Characterization of energetic and thermalized sputtered tungsten atoms using tuneable diode-laser induced fluorescence in direct current magnetron discharge Plasma Sources Sci. Technol. 24015012

[20] Desecures M, de Poucques L, Easwarakhanthan T and Bougdira J 2014 Characterization of energetic and thermalized sputtered atoms in pulsed plasma using time-resolved tunable diode-laser induced fluorescence Appl. Phys. Lett. 105181120

[21] Esteve J, Zambrano G, Rincon C, Martinez E, Galindo H and Prieto P 2000 Mechanical and tribological properties of tungsten carbide sputtered coatings Thin Solid Films $373282-6$

[22] Granqvist C G 2000 Electrochromic tungsten oxide films: review of progress 1993-1998 Sol. Energy Mater. Sol. Cells $60201-62$

[23] Lee J, Chen J and Leanhardt A E 2013 High resolution isotope shifts and hyperfine structure measurements of tungsten by laser-induced fluorescence spectroscopy J. Phys. B: At. Mol. Opt. Phys. 46075003

[24] Stepanova M and Dew S K 2004 Anisotropic energies of sputtered atoms under oblique ion incidence Nucl. Instrum. Methods Phys. Res. B 215 357-65

[25] Rossnagel S M, Cuomo J J and Westwood W D (ed) 1990 Handbook of Plasma Processing Technology: Fundamentals, Etching, Deposition, and Surface Interactions (Norwich, NY: William Andrew) 